\title{
THE
}

\section{FOOD OF PLANTS}

A. P. LAURIE

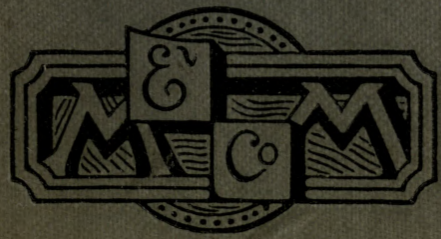


THE FOOD OF PLANTS 


\section{THE}

\section{FOOD OF PLANTS}

\section{AN INTRODUCTION}

TO AGRICULTURAL CHEMISTRY

BY

A. P. LAURIE, M.A., B.SC.

Fellow of King's College, Cambridge

\section{WITH ILLUSTRATIONS}

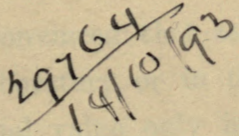

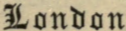

MACMILLAN AND CO.

AND NEW YORK

I 893 



\section{PREFACE}

THIs little book has been written as an experimental introduction to Agricultural Chemistry for beginners, and I have therefore not assumed any knowledge of chemistry on the part of the reader. On the other hand, he will have, in the course of carrying out the experiments described in the text, occasionally to perform operations which he cannot fully understand the meaning of without some little knowledge of chemistry. It would, therefore, be advisable to combine the study of the Chemistry Primer with the study of this book.

I have been long convinced that science can be taught only in the laboratory or in the field, and that it is of educational value only in so far as it presents a logical course of reasoning based on experiment to the young student. Accordingly I have tried, as far as possible, to keep this method of instruction in view, though I have been compelled, especially in the last chapter, to give a good deal of general information for which experimental proof 
is wanting in the text. On the whole, however, an experimental course has been developed in the series of lessons.

The book is intended neither for reading in the study, nor for supplying suitable experiments for the lecture table. The student is supposed to himself perform the experiments under the guidance of a teacher. With this in view, I have taken pains to make the experiments simple, and the materials required inexpensive, so that all classes of schools might find the course of instruction within their capacity and their means.

A student who has been carefully through the experiments will find that he can read a work such as Fream's book on Agriculture with intelligence. He will not, however, be able to pursue the study of the chemistry of agriculture further, in a thorough and scientific sense, without first mastering the principles at least of chemistry. He should, accordingly, be familiar with Roscoe's Elementary Chemistry, or a work of similar character, before involving himself in the chemistry of agriculture.

I cannot conclude without thanking Mr. Wallace, Professor of Agriculture in the Edinburgh University, for the valuable assistance he has given me with the proofs.

A. P. LAURIE. 


\section{CONTENTS}

\section{CHAPTER I \\ THE PLANT AND WATER}

Introduction

The Root

The Plant requires Water .

The Plant Drinks through the Roots

The Water passes up from the Roots through the Stem and into the Leaves . . . . . 4

The Water passes off from the Plant into the Air by Openings in the Leaves

\section{CHAPTER II}

THE FOOD OBTAINED BY THE PLANT FROM THE SOIL

Some Substances are Soluble in Water . . . 11 Soluble Substances can pass into the Roots . . 13 The Food is left in the Plant when the Water evaporates 14 The Soil is partly Soluble in Water . . . 15 The Plant Food in the Soil is only slightly Soluble . 17 


\section{CHAPTER III}

THE NATURE OF THE SOIL

PAGE

The Soil contains Sand and Clay . . . . 21

The Improvement of Clay Soils . . . . . 22

The Amount of Water in the Soil . . . . 22

The Soil should not contain too much Water . . 24

The Soil contains decaying Remains of Plants called

Humus . . . . . 25

The Subsoil contains little Vegetable Matter . 26

The Way the Soil has been Formed . . . 27

\section{CHAPTER IV}

THE SUBSTANCES OF WHICH A LEAF IS COMPOSED

Four-fifths by Weight of the Leaf is Water . $\quad 30$ The Leaf contains Water, Charcoal, and Ash . . 31

Part of the Food of Plants from broken-down Rocks . 31 The Effect of Farming on the Soil . . . . 31

How the Exhaustion of the Soil is Prevented . . 33 The Ash contains among other Substances Potash and Phosphoric Acid . . . . . 34

\section{CHAPTER V}

HOW PLANTS OBTAIN FOOD FROM THE AIR

The Seed obtains Food from the Air . 40

The Food obtained from the Air is Charcoal . . 40

The Air is Altered by Burning Substances . . . 43

The Air is Changed by the Breathing of Animals . . 44

Vitiated Air restored by Plants in Sunlight . . 45 


\section{CHAPTER VI}

THE COMPOSITION OF THE AIR AND THE PREPARATION OF CARBONIC ACID GAS

PAGE

The Action of Vitiated Air on Lime Water . . 48

Vitiated Air is Produced by burning Charcoal . . 48

The Charcoal combines with the Air to form a Gas . 50

The Action of burning Phosphorus on Air . . . 51

The Phosphorus removes Part of the Air . . $\quad 52$

The Air contains two Gases, Oxygen and Nitrogen . 55

Oxygen set Free by Plants in Sunlight . . . 56

\section{CHAPTER VII}

THE NITROGEN REQUIRED BY PLANTS

Ammonia contains Nitrogen . $\quad$. $\quad .58$

Plants cannot absorb Nitrogen directly . $\quad$ • 59

The Natural Order, Leguminosæ, and the Absorption of

Nitrogen $\quad . \quad$. $\quad$. $\quad$ • 59

Nitrogen Compounds obtained from the Decay of Plants . 60

Nitrogen Manures . . . . . 60

Conclusion

\section{APPENDICES}

I. NOTES ON THE EXPERIMENTS

II. ON THE USE OF THE BALANCE

List of Apparatus and Chemicals required . 



\section{CHAPTER I}

\section{THE PLANT AND WATER}

\section{Introduction}

A WHEN we walk through the country we see the flowers growing in the gardens, the trees growing in the forest, the grass growing in the meadow, the corn growing in the field. All these different plants require food or they would not live and grow; and yet they do not feed in the same way as animals, for they cannot walk about in search of food, nor have they a mouth and teeth to eat with.

Let us try and. find out where a plant gets its food, and what sort of meat and drink it requires.

If we take a seed and put it in the ground, we shall find after a few days that the seed has begun to sprout and throw out little green leaves. The young plant has begun to grow, and must be getting food in some way to build up leaves and stem. Now pull it up, and you will find that besides pushing up leaves above ground into the open air it is 
pushing a root covered with fine hairs down into the ground. The young plant must be getting its

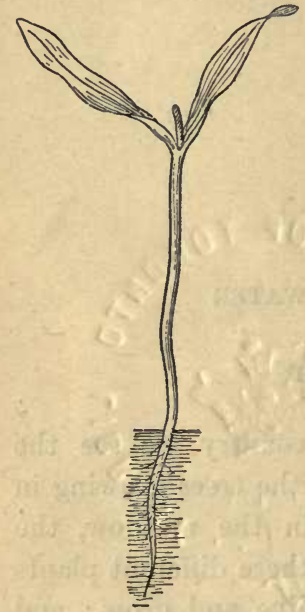

FIG. 1. food either through the roots or through the leaves; or perhaps by means of both.

We have then one part of the plant, the root, below ground, and another part, the stem and leaves, above ground. We shall look at each of these parts by themselves, and try and find out if they have anything to do with getting food for the plant.

\section{The Root}

Let us begin by looking at the root. You will notice at once that it is covered with little branch roots or hairs; pushing their way into the earth in all directions, as if in search of something. We do not yet know, however, if this root is searching for and obtaining food for the plant. Let us try and find out, by making a few simple experiments.

\section{Experiment 1}

Pull up a plant, cut the root off, and then plant it again. In a short time the plant will wither and 
die, showing that the root was probably getting food for the plant out of the earth. In some cases, it is true, if we cut a slip from a plant and put it in the ground, it will live and grow, but this is because fresh roots are formed at the end of the slip under the earth, and pushed out into the soil. We may therefore conclude that without a root a plant cannot live.

\section{The Plant requires Water .}

In order to live we require both food and drink, and would soon die if deprived of water. Let us see if water is required by the plant.

\section{Experiment 2}

In order to find out if a plant requires water, place one in a flower-pot, and keep it without water for a few days. It will soon wither and die, showing that it cannot live without water. If a flower is placed under shelter where the rain cannot fall on it or moisture reach it, you must water it every day, or it will die. In England the trees and grass and flowers get all the water they require from the rain, but in some countries where there is little or no rain, canals have to be dug, bringing water from a river or some other source, to supply the plants. 


\section{The Plant Drinks through the Roots}

Having found out that the plant must have a root and be supplied with water, we now wish to know whether the plant drinks up the water through the roots or gets it through the leaves.

\section{Experiment 3}

In order to find this out, place a plant in a flower-pot, under shelter, and water it every day, taking care not to wet the leaves, but only the earth round the roots. The plant will grow well, showing that the roots, and not the leaves, suck in the water that the plant requires.

This water is obtained by the roots from the soil, which is nearly always moist a little below the surface, holding the water just as a sponge does.

The Water passes up from the Roots through the Stem and into the Leaves

Let us try some more experiments, so that we may make sure that the water is drawn up by the roots and find out what becomes of it.

\section{Experiment 4}

Pull a young plant up by the roots, and shake it gently so as to remove the earth, and then place 
it in a vessel containing some water in which a little eosine red $^{1}$ has been dissolved.

The water, you will notice, is coloured a bright red by the eosine, and we shall therefore be able to tell if the water is sucked up by the roots, because if it is we should be able to follow its path through the plant by means of the red dye.

We cannot see anything going on at first, but if we examine the plant after some twelve hours we shall find all the fine veins in the leaves stained red, showing that the water, carrying with it the dye, has passed through the roots, up the stem, and into the leaves.

Let us now vary this experiment, and see what we can learn from it.

\section{Experiment 5}

Take a young plant as before, and shake off the soil from the roots. Next take a bottle with a fine tube fixed in near the bottom, and rising up the side of the bottle, as shown in the drawing. Then boil some water, cool it, and pour it into the bottle, so as to fill it up to the neck. Next place the roots of the plant in the bottle, and run some melted bees'-wax into the neck of the bottle round the stem of the plant.

The plant is now cemented into the bottle. Place the plant out in the sun, taking care to shade

1 A penny packet of aniline dye will do. 


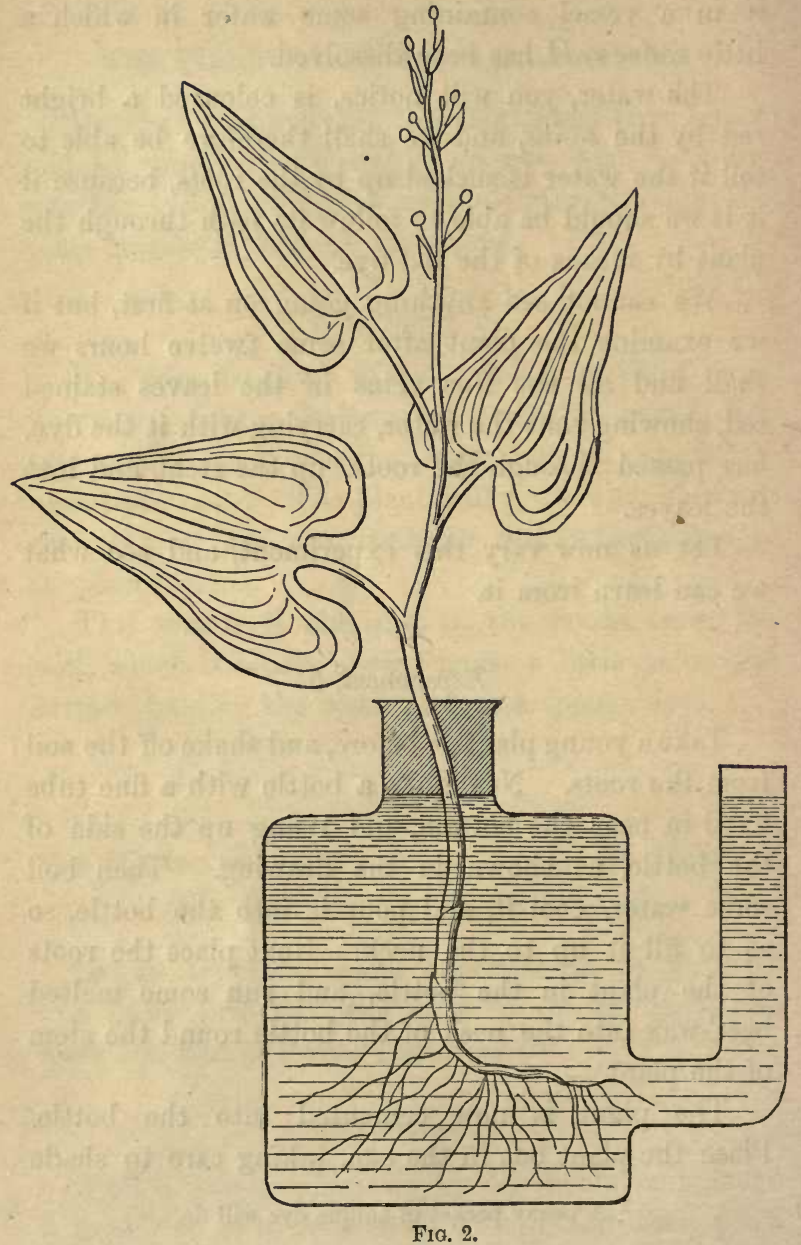


the bottle from the sun's rays. In a short time you will notice that the water is falling in the side tube, showing that the plant is rapidly drawing up water. You will find that the plant will live for some days, the water sinking meanwhile lower and lower.in the tube and in the bottle.

The plant is evidently then taking up a great deal of water, and constantly doing so. Where does this water go to? Does it remain in the plant, or pass off into the air?

We can easily find out if the water remains in the plant or not, by weighing the plant and bottle full of water at the beginning of the experiment, and again at the end of the experiment. If it weighs the same at the end as it did at the beginning, the water has evidently passed from the bottle into the plant and stayed there. If it weighs less, the water must be in some way escaping from the plant.

The Water is passing off from the Plant into the Air by Openings in the Leaves

\section{Experiment 6}

In order to find this out, we can repeat the last experiment in a slightly different way. Break a small branch covered with leaves from a bush, and take a wide-mouthed bottle fitted with a cork. Drill a hole in the cork large enough for the branch 
to pass through. Cut the cork in half through the

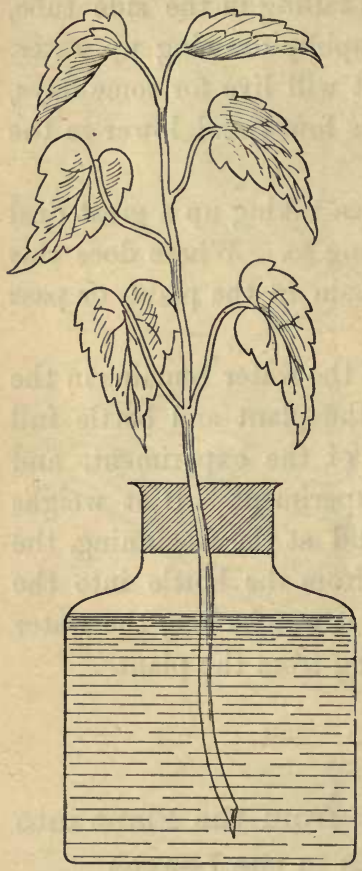

FIG. 3. middle of this hole. Fit the cork closely round the branch. Nearly fill the bottle with water, and insert the cork with the branch. Place the bottle on a balance, weigh it, and note the weight. Then take the bottle off the balance and place it out in the sun as before. In a short time the water will begin to sink in the bottle, showing that the broken end of the stem is able to draw up the water. After it has been for a few hours in the sun weigh again. It now weighs much less, showing that the water has escaped into the air.

If we now pick off the leaves, the water will practically cease sinking in the bottle, and the bottle will no longer lose weight appreciably.

Evidently then the water is escaping from the surface of the leaves, and as it is not dripping from them, it must be passing off in the form of vapour. 
That water-vapour is escaping from the leaves can further be shown by a very simple experiment.

\section{Experiment 7}

Pick a fresh green leaf, and lay it lightly back

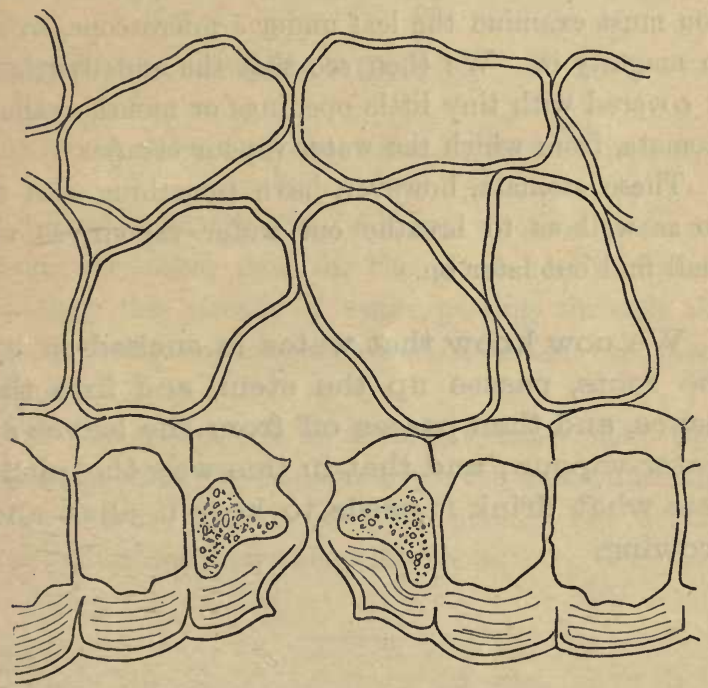

Fig. 4.-Section of leaf showing stomata.

downwards on a polished piece of metal (the lid of a tin can). After a few seconds pick it up again. The metal surface under the leaf is covered with little drops of water, owing to the escaping vapour condensing on the cold surface.

Now turn the leaf over, and place the front or 
upper surface on the metal surface. Very little water will now be found on the metal, showing that most of the water-vapour is escaping from the under surface of the leaf.

In order to find out why the water escapes from the under surface more than from the upper surface, you must examine the leaf under a microscope, so as to magnify it. We then see that the under surface is covered with tiny little openings or mouths called stomata, from which the water-vapour escapes.

These stomata, however, have something else to do as well as to breathe out water-vapour, as we shall find out later on.

We now know that water is sucked in by the roots, passes up the stem, and into the leaves, and then passes off from the leaves as water-vapour; and that in this way the plant gets what drink it needs to keep it alive and growing. 


\section{CHAPTER II}

THE FOOD OBTAINED BY THE PLANT FROM THE SOIL

WE must next try and find out whether the roots obtain any other food for the plant besides water; whether the stream of water passing through the plant carries anything else with it which the plant requires.

We have noticed in a former experiment that when the water was coloured red, the water took the red colouring with it into the plant. Let us try and understand how this came about.

Some Substances are soluble in Water

\section{Experiment 8}

Take five small flasks, and place in one some sugar, in the next some salt, in the next some blue crystals of sulphate of copper, ${ }^{1}$ in the next some sand,

${ }^{1}$ Sulphate of copper is poisonous. 
in the next sorne whiting, and then add some water to each and warm them gently over a spirit-lamp. The salt, the sugar, and the sulphate of copper disappear from sight; the sand lies at the bottom unchanged; and the whiting mixes with the water, but the water does not become clear. Now taste the sugar water and the salt water. Evidently from the taste the sugar and salt are still there, and the blue colour of the sulphate of copper water shows that the sulphate of copper also is still there. These three substances have dissolved in the water. The sand and whiting have not done so.

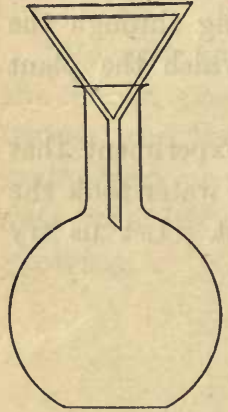

FIg. 5.

Now place five glass funnels in a row, and fit a piece of filter-paper into each, and empty the flasks, each into a separate funnel.

The water comes through clear in each case; but on tasting the sugar water and salt water, we find that the sugar and salt have passed through the paper with the water. The sulphate of copper water is still blue in colour, showing that the sulphate of copper has passed through. But the sand and the whiting have been left behind on the paper. It is now clear what we mean when we say a substance dissolves or is soluble in water. 
II FOOD OBTAINED BY THE PLANT FROM SOIL 13

Soluble Substances can Pass into the Roots, but Insoluble Substances cannot Pass into the Roots.

\section{Experiment 9}

Now mix a little eosine red in water and filter. The eosine red dissolves and passes through the filter-paper. We thus see that the eosine red which we already know can pass into the roots is also soluble in water. Let us then see if a colour which does not dissolve can pass into the roots also.

\section{Experiment 10}

Take a little red lead and mix it with water and filter it. The red lead remains behind on the filterpaper, showing that it does not dissolve. Now mix some more red lead with water and dip the roots of a plant into it, as you did in the case of the eosine experiment. When we look at the plant next day the veins of the leaves have not been coloured red, showing that the roots cannot take up the red lead because it does not dissolve in the water.

We thus see that some things dissolve in water, and can then pass through filter-paper and pass into the roots of the plants ; and that other things do not dissolve in water, and cannot pass through filter-paper or into the roots of the plants. 
The Food is left in the Plant when the Water evaporates

We now understand that any food the plant obtains from the soil must first be dissolved in the water, and that it can then pass up into the plant. We also have learnt that the water evaporates from the surface of the leaves. Let us see what will

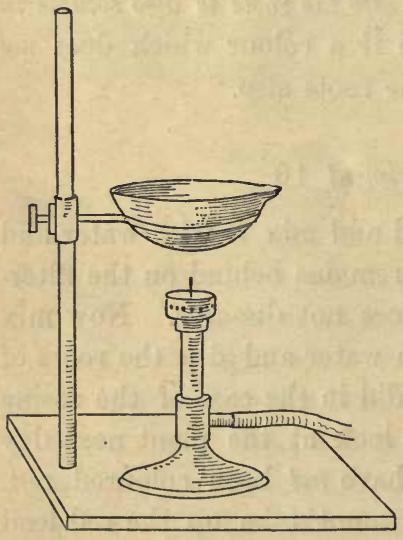

Fig. 6. become of the sub. stances dissolved in the water when this happens.

\section{Experiment 11}

To find this out, pour the water containing the salt, the sugar, and the sulphate of copper into three porcelain evaporating basins, and place the basins over a lamp. The water will soon boil away, leaving the salt, sugar, and sulphate of copper behind in the porcelain dishes.

We may see from this experiment that substances dissolved in the water that is always passing into the roots will remain behind when the water evaporates from the leaves. 
II FOOD OBTAINED BY THE PLANT FROM SOIL 15

Now if we suppose the soil to contain food for the plant, which food is soluble in water, we can understand how the plant may be fed by this means.

The roots are always sucking up water, which passes through the plant and evaporates from the leaves, and this continuous stream of water leaves behind the food it brings with it, so that the plant is continually being supplied with fresh food.

\section{The Soil is found to be partly Soluble in}

\section{Water}

Let us now examine the soil itself to see if any part of it is soluble in water or no.

\section{Experiment 12}

In order to find out what part of the soil is soluble in water, take a little garden mould and shake it up for some time with distilled water, and let it settle. The clear water contains the part of the soil which is soluble dissolved in it, and the rest has settled down.

Pour off the clear water into a small evaporating basin and place the basin over a spirit-lamp. The water will soon boil away, leaving a powder in the bottom of the dish. This powder is the 
soluble portion of the soil, a portion of which passes through the roots of the plant and forms part of its food.

We have now found out not only that the roots suck up water for the use of the plant, but that this water contains certain parts of the soil dissolved in it which are used by the plant as food.

In the last experiment we used distilled water to dissolve part of the soil. Why did we not use ordinary tap water? and what do we mean by distilled water?

\section{Experiment 13}

Take some tap or well or river water, place it in the porcelain dish and boil it away. There is, you notice, a residue left. Evidently the water was not pure. Some things were dissolved in it which were left behind when it was boiled away. We could not therefore use this water for our former experiment, as it is not sufficiently pure, and must therefore obtain some pure water.

You have noticed that in boiling the water the substances dissolved are left behind. If, then, we could collect the steam which is passing away and condense it - that is, bring it back into liquid again -we should obtain pure water.

We can do this quite easily by the following arrangement :- 
II FOOD OBTAINED BY THE PLANT FROM SOIL 17

\section{Experiment 14}

Place water in the retort $A$, and push the neck of the retort into the condenser $\mathrm{B}$. This condenser is

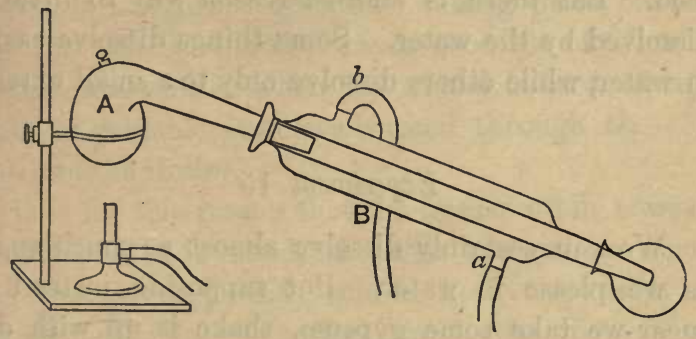

Fig. 7.

arranged so as to allow a stream of cold water to flow in at $(a)$ and out at $(b)$, through the outer tube, while the steam from the water in the retort passes down the inner tube and is thus cooled and condensed.

Now place a lamp under $\mathrm{A}$ and let the water boil vigorously. Soon drops of water will fall from the end of the condenser into the flask. This is pure or distilled water, obtained by condensing the steam coming from the retort by means of the condenser.

The Plant Food in the Soil is only slightly Soluble

On boiling away the water which had been shaken up with the garden mould, very little residue, we found, was left (Experiment 12). 
From this it would seem that there was very little store of plant food in the soil; and it is true that the greater part of the soil is useless as plant food. But there is another reason why so little is dissolved by the water. Some things dissolve easily in water, while others dissolve only to a small extent.

\section{Experiment 15}

We can certainly dissolve almost as much sugar as we please in water. But supposing instead of sugar we take some gypsum, shake it up with distilled water, and filter. Apparently the gypsum has not dissolved at all. However, we must make sure. Boil the filtered water away, and notice that a slight deposit is left, showing that the water has dissolved a very little, but only a very little, of the gypsum. If we continued to shake up the gypsum, always adding fresh water, each supply of water would dissolve a little more, until all the gypsum was dissolved. In the same way the soil contains a store of plant food which is only dissolved little by little, year by year. Furthermore, there are slow changes going on in the soil which are changing valuable plant food from an insoluble into a soluble state, and so making it available for use by the plant.

We can now understand how the roots are supplied with food from the soil.

The rain soaking into the earth dissolves such soluble substances as it contains, and these are sucked 
up by the roots along with the water. Some of them may be of no use to the plant, but others are used by the plant in building up root, stem, and leaves.

While a vigorous growth is taking place on the soil this dissolved food is made good use of ; but in autumn and winter, when the ground is bare, certain kinds of valuable food are washed through the soil and into the drains.

It is for this reason that the farmer often sows a catch crop, as it is called, of Italian rye grass or some other forage crop, which, coming up in September or October, occupies the surface and sucks up the food in the soil. In the spring this catch crop is ploughed in as green manure, and, rotting, returns to the soil the food, stored in it through the winter, in time to feed the young plants which are sown in spring.

We have now learnt that there are certain substances in the soil, soluble in water, which are absorbed by the roots and are used as food for the plant. 


\section{CHAPTER III}

THE NATURE OF THE SOIL

WE have now learnt that the plant obtains food from the soil, and shall therefore next try a few experiments with a view to finding out something about the nature of the soil itself.

\section{Experiment 16}

Take a little dry garden soil and rub it down in a mortar, and then sift it through some muslin. Notice the small stones and pieces of root and blackened portions of plants left in the muslin. Clean the mortar and place the sifted soil back in it, and half fill the mortar with water, and grind the soil and water together; then pour the muddy water off into another vessel, taking care to leave the soil that settles to the bottom in the mortar. Do this several times with fresh water until the water comes off clean and is no longer muddy. Examine the soil left in the bottom of the mortar and you will notice that it consists of sand. 
Allow the mud in the water you poured off to settle, and then pour the water off. On examining the mud you will find it to be a fine sticky clay. We have thus separated the soil roughly into stones, remains of plants, sand, and clay.

If we examine soils brought from different places we shall find different proportions of sand and clay, some containing a large quantity of clay being called heavy clay soils, others containing a large proportion of sand being called light sandy soils. $^{1}$

Sand alone forms a very loose, powdery soil, in which the roots of the plants get little hold. Water also passes through it quickly, as we can easily prove by fashioning the sand into a hollow cup and pouring water into it.

Consequently sandy soil dries up quickly, and the plants growing in it suffer from want of water.

Clay, on the contrary, will not allow water to . pass through it easily. If we model a little cup out of clay, and fill it with water, it will remain there and not drain through, as is the case with the sand. A clay soil does not let the water pass freely through it, so that it may dissolve food for the plant, and supply the roots.

A good soil, therefore, is a mixture of both these bodies in suitable proportions.

1 "Heavy" here means difficult to plough, "light" easy to plough. Bulk for bulk, sandy soils weigh more than clay soils. 


\section{The Improvement of Clay Soils}

If we take a piece of clay and heat it red hot, when it cools it will no longer knead up with water as before. A common red flower-pot, or a brick, is such a piece of baked clay.

Pound a piece of brick into a fine powder in a mortar and then mix it with water. It behaves like sand, and allows the water to pass freely through.

Sometimes, therefore, when the soil contains too much clay, the farmer pares off the surface, gathers the clay of the subsoil into heaps, and burns it, and then returns the baked clay to the soil.

This baked clay acts like a mixing of sand with the clay, and keeps the soil open, so as to allow water to pass more freely through, and dissolve the food necessary for the plant.

\section{The Amount of Water in the Soil}

\section{Experiment 17}

Let us now take a moist piece of garden soil and try and find exactly how much water it contains.

To do this properly, we must make it hot enough to drive off all the water, but at the same time we must not heat it too strongly, as you will see presently. 
We had best, therefore, heat it to exactly the temperature at which water boils. We shall then be sure that the water is driven off, and at the same time not make it hotter than is necessary. We can do this most easily by drying it in a water-bath.

That is to say, you place the mould in a metal case surrounded by water contained in an outer case, and heat the whole apparatus over a flame.

The water in the outer case boils and heats the soil to just the right temperature.

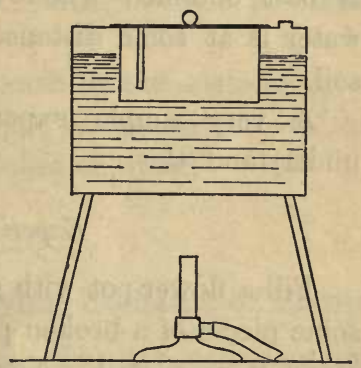

FIG. 8.

Weigh out about one ounce of the soil in a tin dish (the round lid of a tobacco tin will do very well), and place it in the inner case of the water-bath, and heat it there for about an hour.

Then take it out, let it cool, and weigh again. It will now weigh much less than before. We cannot, however, be sure that all the water is gone. Put it back in the water-bath, heat for another half hour, and again weigh.

If the weight is the same as in the second weighing, we may be sure that all the water is gone. The soil will lose perhaps 15 or 20 per cent of its weight, showing the amount of water it contains. 


\section{The Soil should not have too much Water}

In order that we may have a healthy growth of plants, the soil should be moist, but not saturated with water, so as to form a swamp. This condition is best obtained when the natural surface of the water is at some distance below the surface of the soil.

A very simple experiment will enable us to understand this.

\section{Experiment 18}

Fill a flower-pot with garden mould, first placing some pieces of a broken pot in the bottom, and then stand it in a pail. Now pour water into the pail until it stands at the level of the top of the earth in the flower-pot.

The water will quickly rise in the pot and turn the earth to mud.

Now pour the water out of the pail, leaving only two or three inches of water behind, and place the flower-pot in the pail again.

A great deal of the water will then drain out of the flower-pot, but the earth in it will remain moist as long as there is any water in the pail.

The earth can evidently soak up the water like a sponge or a piece of blotting-paper.

To make sure of this, take another pot and fill it with dry earth, and place it in a pail with two inches of water. 
In a short time the water will have soaked up and moistened the dry soil to the top.

When, therefore, the natural level of the water is too near the surface of the soil, thus making it swampy, the farmer lays drains in the ground, which drain away the water until it is at the level of the drains.

The soil is then kept moist by the soaking up of the water from this level, just as in the case of the flower-pot placed in two inches of water.

The Soil contains Decaying Remains of Plants

We have already found that the soil contains roots and portions of plants. These decay, forming a black substance called humus, which will burn away if the soil is heated.

\section{Experiment 19}

Take a portion of garden soil, dry it in a water - bath, and sift it through muslin. Next take a crucible or a piece

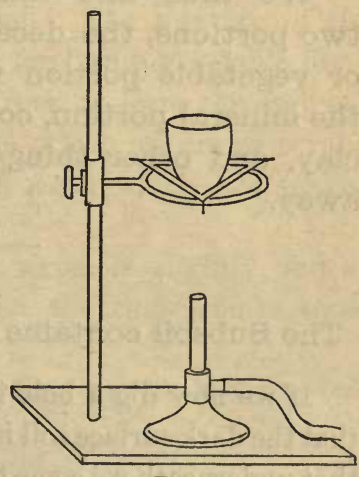

FIG. 9. of platinum foil about three inches by four inches, and bend up the edges so as to 
make a shallow tray, and put it on the balance and weigh it carefully. Note the weight. Put some of the dried soil in it and weigh again. Subtract the first weight from the second, and thus get the weight of dried earth.

Place the crucible or platinum dish on a pipeclay triangle over a Bunsen flame or petroleum blowpipe, and heat it strongly.

The soil begins to smoke and burn.

Keep up the heat until no more smoke is given off, let it cool, and weigh it again. Again heat and again weigh until the weight remains the same. It is now much lighter than it was before, owing to the loss of all the decaying remains of plants which have been burnt away.

We thus find that the soil consists of two portions, the decaying remains of plants or vegetable portion which burn away, and the mineral portion, consisting of sand, stones, clay, and other things which does not burn away.

\section{The Subsoil contains little Vegetable Matter}

If we now dig a hole in the garden, we shall find that the dark surface soil is only a few inches deep, and that underneath we come to earth of a different colour.

This is called the subsoil, and contains very little decaying vegetable material. 
Take a little of this subsoil, dry it, and repeat the preceding experiment. It does not smoke, and loses very little in weight, showing that it consists almost entirely of mineral, and not of vegetable, substances.

If we dig deeper still, we shall find the rock by the crumbling of which the soil was first formed.

\section{The Way the Soil has been Formed}

We can now understand how the soil has been formed. We must imagine a hard surface of rock where now there is soil. This rock has slowly crumbled to powder, forming the mineral portion of the soil (sand, clay, etc.). Plants sown by chance seeds have sprung up, died, and decayed, forming the vegetable portion of the soil. The mixture of the two forming a soil suitable for future vegetable life.

The crumbling of this rock to form the soil has been caused partly by the action of air and rain, but also by the freezing of water which has soaked into the pores of the rock.

When water freezes it expands slightly, and so splits up the rock. When the thaw comes those broken-off pieces fall apart. .

This action of freezing water can be easily tested.

\section{Experiment 20}

Take a small narrow-necked glass flask, and fill it with water, and place it in a vessel containing a 
mixture of ice and salt, and leave it there for a few minutes. The water in the flask will soon freeze, and on lifting it carefully out, you will find the flask has been split in tiny pieces by the expanding water.

Not only are the rocks thus broken up, but the stones and coarser pieces of soil are crumbled finer and finer every winter by the action of the frost. The particles of dense clay are also separated, and the surface is left in a powdery or tilthy condition suitable for a seed-bed.

When the rain falls upon this finely-powdered rock the water dissolves the soluble portions, and the roots can penetrate more easily in all directions in search of food.

We have learnt that the soil is a mixture of broken-down rock and of decayed vegetable stuff, and we have divided the mineral portion roughly into sand and clay.

We have also learnt that the soil can suck up moisture, and why it is drained.

We can now understand how the soil has been slowly formed by the action of rain, air, and frost, and the decaying of plants, passing gradually from hard rock to rich garden mould. 


\section{CHAPTER IV}

THE SUBSTANCES OF WHICH A LEAF IS COMPOSED

WE can readily understand that the decaying vegetable stuff supplies food for the plant, but we have not yet decided whether the broken-down rock also supplies it with food.

We can best decide the matter by examining a leaf itself, and seeing of what it is composed.

\section{Experiment 21}

Pick a few leaves and weigh them. About one quarter ounce is sufficient. Put them in a warm dry place for a short time and weigh again. They are now lighter than before, having lost some of the water they contain. Place them in a water-bath over a lamp, so that they may be heated to the temperature at which water boils, and leave them there for two or three hours; then remove and weigh again. They are now dried up and will only weigh 
about one-fifth part of what they weighed before; all the water having been driven off in vapour.

We thus see that four-flfths, by weight, of the leaf is water.

Take a piece of platinum foil about four inches by three inches, and bend up the edges so as to make a little platinum dish.

Weigh it and note the weight.

Place the dried leaves in it and weigh again. By subtracting the first weighing from the second we find the weight of the leaves. Place the platinum tray on a pipeclay triangle over a Bunsen burner or petroleum blowpipe, and light the gas.

The leaves will burst into flame and burn for a short time. When the flame has died away remove the burner and notice the charred bits of leaf in the tray. This charred leaf is charcoal. We have now reduced the leaf to charcoal.

Replace the lamp, and arrange it under the dish so that the platinum becomes red hot.

The pieces of leaf glow, the charcoal burns away, and a pinkish ash is left behind.

This ash is the unburnable or mineral part of the leaf.

Allow the platinum dish to cool and weigh again, and subtract the weight of the empty dish. This gives us the weight of the ash, which is a very small fraction of the weight of the dried leaves.

We see from these experiments that the leaf consists of- 
Water, about four-fifths.

A portion that burns away with flame.

Charcoal.

Ash.

Part of the Food of the Plant is derived from broken-down Rocks

These experiments have shown us that the plant consists of a portion that can be burned away, and another or mineral portion, the ash, which cannot be burned away.

The material contained in the ash (which is a mixture of several things, as we shall see presently) must come from the mineral portion of the soil, the broken-down rocks, of which that portion of the soil is composed.

Let us consider, just now, only this part of the food of the plant, - the part derived from the crumbled rock of which the soil is partly composed, and conveyed in solution in water into the plant.

If we search in the soil for the mineral substances contained in the ash of the plant, we find that they are present in an available form in very small quantities, so that they will be temporarily used up if plants are grown repeatedly on the same soil, and then removed.

\section{The Effect of Farming on the Soil}

Now let us try and understand what will happen on a piece of wild uncultivated land. The plants 
growing there-grass, trees, bracken, gorse, and numerous weeds-will suck up through their roots the mineral food they require, and which exists along with the sand and clay of the soil. And when they die, they will decay upon the soil, and replace the mineral food they have taken from it, ready to be used again by fresh plants. The soil will therefore remain rich in the food the plant requires, whether it be mineral or decaying vegetable matter.

Let us now suppose this land to be brought under cultivation by the farmer.

He grows crops upon it of wheat, grass, turnips, and other things. When these are ripe, he does not leave them to decay on the land, but takes a large part of them away. In the case of wheat he takes away the straw and ear, but leaves the roots. In the case of potatoes he takes away the tubers, but burns the leaves and stems on the field and returns the ashes left by them to the soil. If he is using land for grazing, the cattle eat the grass and return a great portion of the food to the soil as dung, but some they keep for building up their own flesh and bone. Thus we find that when soil is being cultivated, a certain amount of the plant food it contains is removed every year, and consequently the soil may get temporarily exhausted. It no longer contains sufficient food to grow good crops. 


\section{How the Exhaustion of the Soil is}

\section{Prevented}

In order to prevent the soil thus becoming temporarily exhausted, the farmer does several things.

(1) He digs or ploughs the land, thus turning up fresh earth for the roots to feed on.

(2) He has found that different crops do not require the same food, and he therefore grows one crop one year and another the next year, rotating his crops.

(3) He allows the land to lie fallow, that is, grows nothing on it at all during a summer season. By doing this he gives time for fresh plant food to become soluble. At the same time a certain amount of food is permanently lost through the drains.

(4) He manures the land, that is, adds to it the food which he believes to be deficient in quantity, for the health and luxuriant growth of his crops.

While he is thus trying to make up for the exhaustion of the soil, he is being assisted by changes taking place in the soil itself.

The earthworms are bringing up fresh soil to the surface from below, and the wind is blowing fresh soil or dust upon the top.

The stones and rocks also are gradually breaking down and supplying the soil with fresh mineral food. This natural process goes on all the more freely if the cultivation is deep, thorough, and frequent. 
The Ash contains many mineral Substances, among which Potash and Phosphoric Acid are of Special Importance

The ash of the plant contains some substances necessary to the life of the plant and some that are not necessary, as has been proved by experiments, in which plants have been grown in water, in which the various substances found in the ash, have been dissolved.

You cannot hope to understand the nature and properties of all these different substances until you are able to study a more advanced book than this.

Let us, however, look at two of these substances, and learn how we can recognise them, namely, Potash and Phosphoric Acid.

(1) The Potash, or "Pearl Ashes" as it is sometimes called, can be easily recognised by the following experiment :-

\section{Experiment 22}

Dip a fine platinum wire in some hydrochloric acid and then in the ash, and then hold the wire in the flame of a spirit-lamp. The flame is at once coloured violet by the potash. Compare this with the flame produced by dipping the wire into the solution in water of a little potash obtained from the chemists, and the same coloration is produced. The potash can be easily separated from the ash of the plant by boiling water. Take some wood 
ashes, boil them in water, filter, and then boil the water away. A white powder will be left, which is potash or pearl ashes.

(2) The Phosphoric Acid can be easily recognised in the ash by the following experiment:-

\section{Experiment 23}

Warm the ash with a little strong nitric acid, add a little water, filter, add a little more strong nitric acid, and some molybdate of ammonia, and warm the liquid gently. A yellow powder is slowly formed in the liquid, thus indicating the presence of phosphoric acid.

Warm in a test-tube in the same way a little phosphate of soda (which contains phosphoric acid), with nitric acid and molybdate of ammonia, and the same yellow powder will be formed.

While these two substances (potash and phosphoric acid) are quite necessary for the plant, they exist in an available form in very small quantities in the soil, and have therefore often to be supplied in manure of different kinds.

For instance, place a little dried horse dung on the platinum foil and heat it strongly. Some ash is left. On testing this in the way already explained (in Experiments 22,23), it will be found to contain both potash and phosphoric acid.

Potash is also often supplied in the form of kainit, sulphate of potash, wood ashes, ashes of plants and 
CHAP.

weeds, etc. etc.; and phosphoric acid in many common manures.

For instance, bones in all the various forms used in agriculture contain large quantities of phosphoric acid in combination with lime. Take a piece of bone, heat it red hot on the platinum foil, and then warm it with nitric acid and test it as before, and phosphoric acid will be found in it.

Another common source of artificial manure are earth phosphates, such as apatite and coprolites; the latter are the fossil remains of fish, and on warming with nitric acid and testing as before, will show the presence of phosphoric acid.

Phosphate slag (formed in certain methods of making steel), will also show the presence of phosphoric acid in the same way.

Sometimes the farmer prefers to have his phosphate soluble in water, in which case the bones or coprolites are treated with sulphuric acid. The experiment may be carried out as follows :-

Take some powdered ignited bone and warm it with a few drops of dilute sulphuric acid and heat till dry. The dry powder left is now soluble in water. Boil with water, filter, and test as before. Phosphoric acid will be found in the solution, while on boiling the bone dust with water, before it has been treated with acid, nothing will be dissolved.

We have now learnt that the plant contains water, charcoal, and a mineral ash, and that this ash contains among other things 
potash and phosphoric acid. We also know that this ash is derived from the broken-down rocks in the soil, and that the available materials supplying it may be temporarily used up if not restored to the soil as manure. 


\section{CHAPTER V}

HOW PLANTS OBTAIN FOOD FROM THE AIR

WE have seen that plants obtain both food and water from the soil by means of the roots. Is this the only way in which they obtain food, or are they also able to feed on air ?

We have often seen mustard or cress grown upon a piece of moist flannel, the tiny seeds springing in a rich mass of green foliage. How have those plants been supplied with food?

Let us try a few experiments with a view to understanding exactly what happens when cress is grown in this way.

But in the first place, let us examine a seed itself, with a view to finding what it contains, and whether it plays any part in feeding the young plant.

If we select a large seed, such as a bean, and cut it neatly in half, we notice in one corner near the margin a small speck. This is the young plant which, if the seed be kept warm and moist, will begin to grow. The rest of the seed is merely a store 
of food, from which the seedling is supplied until it can obtain food for itself.

This food store may be largely oil, as in linseed, or starch and other vegetable substances.

\section{Experiment 24}

Let us take, for instance, some linseed and crush them in a mortar. Now place the crushed seed in a bottle, pour a little ether upon it, cork the bottle and shake it vigorously. After shaking it for a few minutes, empty the contents of the bottle on a filterpaper, and collect the ether running through. Place the ether out in the sun, exposed in a shallow dish. In a short time the ether will evaporate and leave behind a yellow oil. This oil has been dissolved by the ether from the seed, leaving behind a browncoloured substance, similar to that of which linseed cake is made by pressing hot seed.

A store of food is therefore contained in the seed, and with this and with water the cress growing on flannel has been supplied. Can we regard such a store of food as sufficient, or must we search elsewhere to find other sources from which the plant has been fed?

Let us try to find out the answer to this question by another experiment. 


\section{The Seed obtains Food from the Air}

\section{Experiment 25}

Pour a little distilled water into a saucer. Weigh out one gramme of mustard or cress seed, and scatter it on some water placed in the saucer. Place the saucer in the window, and keep it well supplied with water. Let the water used be distilled, so that it may contain no food for the young plant.

The seeds will soon begin to sprout and grow. When they have grown to a full crop remove the young plants, place them in the platinum tray, add the water the saucer contains, and then place them in the water oven, dry them completely, so as to remove the water they contain, and then weigh.

The dried plants will weigh more than the seed, showing that the seeds cannot have supplied all of the material used in the growth of the plant.

The seeds themselves contain a little water, losing, on drying, about 15 per cent of their weight. Consequently, in order to compare exactly the weight of the seed with the weight of the plants, this should be allowed for.

\section{The Food Obtained from the Air is Charcoal}

Now let us go a step farther, and try and determine the nature of the food obtained by the plant from the unknown source. 
We noticed before, on heating some dried leaves, that they were largely composed of charcoal.

If we heat the cress seed strongly we can also change it into charcoal.

The best way to do this is to place half a gramme of the cress seed in a test-tube, and lead into the test-tube a stream of gas obtained by pouring an acid on chalk. This gas passing through the test-tube will prevent the charcoal formed from burning away and so leaving nothing but ash when the test-tube is strongly heated.

In order to obtain this gas, take a wide-mouthed bottle fitted with an indiarubber cork in which two holes have been bored. Fit a bent glass tube into one hole, and a thistle funnel into the other. Place in the bottle some

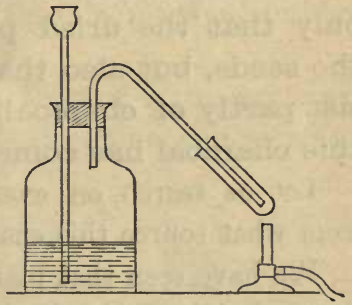

Fig. 10. pieces of broken marble and a little water. Fit into the bottle the cork. Take another piece of glass tubing about nine inches long and connect it by a piece of india-rubber tubing to the bent tube through the cork.

Now pour some strong hydrochloric acid down the thistle funnel. The acid at once begins to attack the marble, and bubbles of gas rise from it, which pass out of the bottle along the glass tube.

Now push the glass tube into the test-tube so as 
to fill the test-tube with this gas, and hold the testtube in the flame of a lamp.

The cress seed begins to smoke. Continue heating it till the smoke ceases to come off, then let it cool, and empty the contents on to a watch-glass.

The seeds have been reduced to charcoal. Weigh.

Let us now heat the dried cress in the platinum dish for a few seconds over a spirit lamp, so as to reduce it to charcoal, and weigh.

The charcoal obtained from the seed weighs a good deal less than that obtained from the dried plants.

We have found by this experiment, not only that the dried plants weigh more than the seeds, but also that the dried plants consist partly of charcoal, and that only some of this charcoal has come from the seeds.

Let us search on every side, and try and find from what source this charcoal can have come.

We have seen that plants are largely composed of charcoal. Are animals also largely composed of this substance?

Let us find out by repeating on a piece of meat the experiment we made with the dried cress.

Smoke is given off, and a mass of charcoal is left behind.

Animals as well as vegetables then can be transformed in part into charcoal.

We have still, however, to find out where the plant obtains the charcoal from, and with a view to helping you towards that discovery, I would ask you to 
notice some curious facts about the burning of different substances.

\section{The Air is Altered by Burning Substances}

You must have often observed that when a fire is burning, the air in the room is drawn into the fire through the bars and then passes up the chimney, and that, if deprived of a plentiful supply of air, the fire would go out.

Let us look into this matter more closely, and try and determine what part the air plays when the wood or coal is burning.

We do not yet know if this air is in any way changed by passing through the flame, and so must try by a simple experiment to find out if any change has taken place.

\section{Experiment 26}

Light a candle and then cover it over with a bell-jar, so as to shut in with the flame a fixed amount of air. At first the flame burns brightly, but soon begins to burn feebler and feebler,

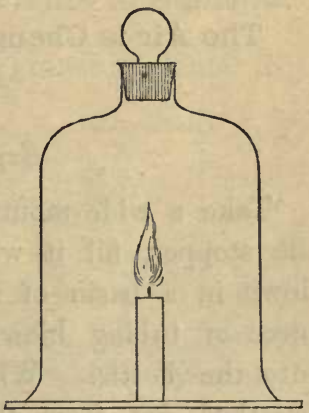

Fig. 11. and then goes out. Now light a match and plunge it into the bell-jar. The match also goes out at once. 
The burning candle has so altered the air that substances can no longer burn in it. We may call this air spoiled, or vitiated air. Having tested the effect of the candle, we can try the effect of spirits of wine, burning paper, burning oil, burning hay, wood, or dried leaves. In each case the result is the same. The air is so altered that it no longer supports combustion.

We find then by these experiments that substances when burnt alter the air in such a way that it will no longer support combustion, that is to say, that nothing will burn in it.

Let us see now if we can obtain vitiated air in any other way.

\section{The Air is Changed by the Breathing of Animals}

\section{Experiment 27}

Take a wide-mouthed stoppered bottle, remove the stopper, fill it with water, and turn it upside down in a basin of water. Then by means of a piece of tubing blow air coming from the lungs into the bottle. When the bottle is full of air breathed out from the lungs, put in the stopper and lift the bottle out of the basin. Light a match, open the bottle, and plunge in the match. The match goes out at once, showing that the 
air coming from the lungs is also vitiated air. We have thus learnt that both the air acted upon by burning bodies and the air coming from the lungs will not support combustion.

If we were to place a living animal in this vitiated air it would quickly die, showing that the vitiated air will not support life.

We see then from all these experiments that breathing animals and burning fires are all preparing this vitiated air, so that we should expect that by this time all the air on the earth would be unbreathable, unless there is some way in which the air can be purified and restored to its former state.

Vitiated Air restored by Plants in Sunlight

Let us see whether it is growing plants that exercise such an influence on the air as to purify it.

\section{Experiment 28}

Place the wide-mouthed bottle, full of water, upside down in the basin as before and fill it with vitiated air from the lungs,

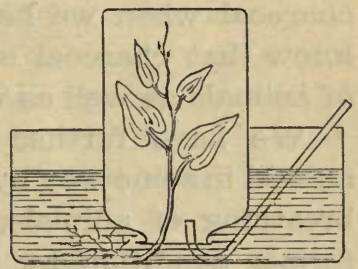

Fra. 12. and then, leaving it standing upside down in the basin, put a young vigorous plant up into it, with the 
roots remaining in the water outside, and expose the whole to the sun.

After exposing all day, remove the plant, stopper the bottle, lift it out, and test the air in it with a lighted match. The match will now burn, showing that the plant acting in sunlight has been able to restore the air to its former state.

We can now easily find out if exposure to sunlight had anything to do with the action of the plant.

Repeat the last experiment, only keep the plant in the dark instead of in the sunlight, and test with the match. The air will remain unaltered and the match will go out, showing that the plant cannot restore the air without the assistance of light.

We have now found that the plant does not obtain all its food from the soil through the roots, but also obtains food from the air, and that we find this food in the form of charcoal when we heat the plant. We also know that charcoal enters into the substance of animals as well as vegetables.

We have further discovered that air is altered in some way by burning bodies, and the breathing of animals, and is restored to its former condition by the action of plants in sunlight. 


\section{CHAPTER VI}

THE COMPOSITION OF THE AIR AND THE PREPARATION OF CARBONIC ACID GAS

We have now learnt two facts about the plant. We know that it obtains charcoal from the air, and we also know that it can restore air, which has been vitiated by burning substances or by passing through the lungs, to its former state.

There is surely some connection between these facts which we should be able to find out.

And first, take note that the substances burnt, whether they be the spirits of wine prepared from fermented corn, or the candle prepared from animal or vegetable fat, were all of animal or vegetable origin, and would probably contain charcoal as one of their parts.

Let us then burn some charcoal and see whether that also produces vitiated air, which can be restored to its pure state by the plant. But before doing so, let us try another test for the presence of vitiated air. 
The Action of Vitiated Air on Lime-Water

\section{Experiment 29}

We have noticed that a candle or match will not burn in vitiated air. It has another property which will be useful in identifying it when we come across it.

If we shake up some lime with water and then filter, we obtain a clear solution of lime in water.

Pour a little of this clear lime-water into a widemouthed bottle, and lower a lighted candle into the bottle and then cover up the mouth. The candle soon goes out.

Remove the candle, replace the stopper in the bottle, and shake up the lime-water with the vitiated air. A white powder is formed, the lime-water becoming milky in appearance.

Now take a fresh supply of lime-water in another bottle, and blow through it. This also becomes milky in appearance, owing to the vitiated air from the lungs.

We have here then a simple means of testing for the presence of vitiated air.

Vitiated Air is produced by burning Charcoal

We have seen that various different bodies in burning produce vitiated air : let us now see whether burning charcoal also does so. 


\section{Experiment 30}

Fill a little brazier with lumps of charcoal and set the charcoal on fire. When it is burning brightly arrange over it a tin funnel with a glass tube passing away at the top to a bell-jar through a cork, and arrange another tube from the top of the bell-jar and connected through a cork with a tin can full of water, with a tap at the bottom. Place a lighted candle on

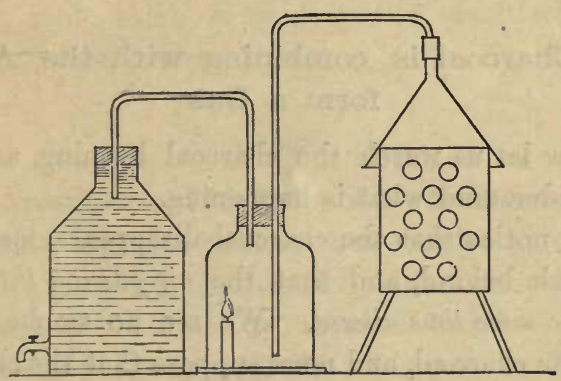

Fia. 13.

a ground glass plate and fit the bell-jar, rubbed round the edge with vaseline, over it, and draw a stream of air through the whole apparatus by turning on the tap of the tin can.

As long as ordinary air is passing through, the candle burns; but as soon as the tin funnel is placed over the brazier, so as to collect the air from the burning charcoal, the candle goes out.

In order that we may be sure of the nature of 
the air coming from the charcoal, place on the ground glass plate a little beaker containing clear limewater, with the tube from the funnel dipping into it, and draw the air through as before. The limewater quickly becomes milky, showing that the burning charcoal is producing the same vitiated air as the burning candle and the breathing animal.

The Charcoal is combining with the Air to form a Gas

Now let us watch the charcoal burning, and try and understand what is happening.

We notice that the charcoal disappears, leaving a little ash behind, and that the air passing through it is at the same time altered. We see no smoke rising from the charcoal, and must suppose that the charcoal passes away with the air as a gas of some kind. We know the air is an invisible gas or mixture of gases. We know that by heating coal in a retort, another invisible gas-coal-gas-is formed. Here also the charcoal and the air seem to form an invisible gas of such a kind that it puts out a burning flame and turns lime-water milky in appearance.

This gas, formed of charcoal and air, seems to act as a food to the plant, the plant taking the charcoal to itself and restoring the air to its former condition. 
We have yet to learn, however, if the whole or only part of the air is consumed in this change as it passes through the burning charcoal.

The Action of burning Phosphorus on the Air

In order to decide this point we shall try some experiments with another substance which burns readily, and which is used in the manufacture of matches, namely, phosphorus.

\section{Experiment 31}

Phosphorus is sold in sticks which are always kept under water, owing to their tendency to go on fire when exposed to the air. Take one of these sticks out of the bottle by means of a pair of nippers or a sharp-pointed penknife, and, placing it under water in a saucer, scrape it clean at one end with the knife, and cut off a little piece, about a quarter of an inch thick, and cut it into four bits. Remove one of these bits with the nippers and dab it gently with blotting-paper to dry it, then place it in a deflagrating spoon. Take the bell-jar used in the last experiment and dry it thoroughly inside and place it on a sheet of window glass carefully dried and remove the stopper from the jar. Light the phosphorus in the deflagrating spoon by touching it with a hot wire, and lower it into the bell-jar till the open- 
ing into the jar is closed by the brass disk attached to the wire handle of the spoon. The phosphorus in burning gives off a copious white smoke, which presently collects into flakes, which fall like snow to the bottom of the bell-jar and collect on the glass plate. When the phosphorus has gone out, remove the deflagrating spoon and test the air left in the belljar with a lighted taper. The taper goes out, showing that the air has again been altered by the burning body. Lift off the bell-jar and the glass plate is seen to be covered with a white snow-like powder.

During this experiment the phosphorus has disappeared and this white powder has been formed, which contains the phosphorus. It, however, must contain something else besides phosphorus, as on weighing it, it is found to weigh more than the phosphorus which was consumed. (This cannot be shown without special arrangements.) Apparently, then, the phosphorus in burning is joining with, or combining with, some other body, which is obtained from the air by which it is surrounded; and it is on account of the absence of this body that nothing will burn in the bell-jar afterwards.

The Phosphorus removes Part of the Air

We can now proceed to vary this experiment, so as to decide definitely whether any part of the air 
is removed during the burning of the phosphorus or not.

\section{Experiment $32^{1}$}

Take a pear-shaped hard glass flask (such as is sold for the preparation of oxygen) and clean and dry it carefully, and fit it with a good tight-fitting cork. Cut one of the quarter bits of phosphorus in half. Examine it to see that it is perfectly clean, $d r y$ it thoroughly, place it in the flask and cork it up.

We have now got air and phosphorus corked up together.

Warm the flask gently over a spirit-lamp, keeping it turning in the hand all the time. The phosphorus will melt, catch fire, and run burning round the inside of the flask. As soon as the phosphorus catches fire, remove the flask from the flame and hold it out at arm's length, and turn your head the other way, still turning the flask in your hand. The flask is very apt to burst at this moment, and should therefore be so held that if it does burst it cannot injure the face.

When the phosphorus has gone out, examine the flask. A streak of unburnt phosphorus will be noticed, showing that the phosphorus has gone out before it was completely consumed. We may therefore assume that it has exhausted the supply of the body in the air necessary for its combustion, or it would not have gone out. The flask also contains

1 This experiment is the invention of Professor Armstrong, F.R.S. 
the same white powder that was formed by the burning phosphorus before (Experiment 31).

Take a pudding basin, nearly fill it with water, and as soon as the flask is cool, plunge the neck under the water, and then carefully ease out the cork, keeping the neck under water all the time. As soon as the cork is removed the water rushes into the flask.

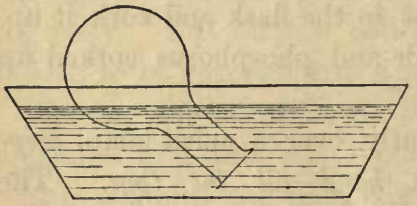

FIa. 14.

Push the cork back again into the neck, lift the flask out of the water, shake it so as to thoroughly cool it by means of the water which has rushed in, plunge the neck under water again, remove the cork as before, and lower the flask into the water until the level of the water inside and outside the flask is the same. Again insert the cork and lift out the flask.

The water has rushed in to occupy the space formerly occupied by the part of the air which has combined with the burning phosphorus. The greater part of the air, however, has evidently remained uncombined. Remove the cork and test with a lighted taper the air which remains in the flask. The lighted taper goes out, showing that this residual air will not support combustion.

We are thus led to believe that the air is a mixture of two gases, one which combines 
with the burning phosphorus, another which does not so combine, and is left behind.

The gas which supports combustion is called

\section{Oxygen}

The gas which does not support combustion is called

\section{Nitrogen}

We can now determine the volumes in which these two gases are present in the air, as the water which has rushed into the flask represents the volume of oxygen which has disappeared. Pour this water into a measuring glass and note the amount. An ordinary ounce-measuring glass will do. Next fill the flask with water, allowing a little for the cork, and empty it into the measuring glass as well, so as to determine the volume of the flask.

On doing this we shall find that the oxygen occupied about one-fifth part of the volume of the flask.

The air therefore contains four-fifths by volume of nitrogen mixed with one-fifth by volume of oxygen.

This experiment gives us an example of what we mean by chemical combination, the oxygen of the air combining with the phosphorus to form a third new body, which we call oxide of phosphorus.

During this operation no substance has been lost or gained, the flask and its contents weighing the same at the beginning and the end of the burning 
of the phosphorus; but at the same time heat has been given out and has escaped. Chemical changes then never result in loss of mass, but often result in the giving out of heat. ${ }^{1}$

\section{Oxygen set Free by the Plant in Sunlight}

We can now understand what was happening while the charcoal was burning. It was combining with the oxygen of the air.

The compound thus formed is known as carbonic acid gas, and is formed during the breathing of animals and the burning of animal or vegetable stuff.

During sunlight, as we have seen, it is absorbed by the plant, the charcoal retained, and the oxygen restored.

That oxygen is thus formed can be easily shown by the following experiment :-

\section{Experiment 33}

Take a tall glass cylinder and fill it with tap water (which contains a good deal of carbonic acid

1 This experiment can also be performed witl greater safety by floating a watch-glass in some water in a dish, placing a piece of phosphorus in the watch-glass, removing the stopper from the belljar used before, lowering the bell-jar over the floating phosphorus into the water, lighting the phosphorus with a piece of hot wire, and inserting the stopper. The way given in the text is neater, and gives a more accurate measurement of the volume of oxygell, but should only be performed by a skilled manipulator. 
dissolved in it), and with fresh green leaves. Put a glass funnel upside down inside the cylinder, and over this an inverted test-tube full of water.

Place the whole thing out in sunlight.

Soon bubbles of gas will begin to rise from the leaves and collect in the test-tube. When enough has been collected, remove the testtube, keeping it closed with the thumb. Turn it up and lower into it a piece of red-hot wood.

The wood will glow brightly, owing to the presence of nearly pure oxygen gas.

We have now learnt that the

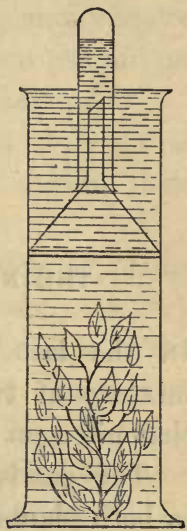

Fia. 15. air is a mixture of two gases, oxygen and nitrogen. That burning bodies are combining with the oxygen to form new substances.

That during the burning of animal or vegetable substances, or the breathing of animals, the charcoal they contain is being converted into carbonic acid gas by combining with oxygen.

That this carbonic acid gas is absorbed by the leaves of plants, and during daylight decomposed, the plant keeping the charcoal and returning the oxygen. 


\section{CHAPTER VII}

THE NITROGEN REQUIRFD BY PLANTS

IN the last chapter we found that the air is a mixture of two gases-nitrogen and oxygen-and that nitrogen forms four-fifths of the air.

This gas is found combined with other substances in both plants and animals, and can easily be recognised.

One of the simplest compounds containing nitrogen is ammonia, which has a peculiarly pungent smell. (For instance, take a little salammoniac and mix it in a mortar with lime. Ammonia is at once set free, and we can notice the peculiar smell of the gas.)

If, then, we find that any substance can be made to yield ammonia, we may take that as a proof that it contains nitrogen combined with other substances.

Now take some seeds of corn, and mix them with a little soda-lime, and heat them strongly in a testtube. Ammonia is set free, and we can smell it coming from the tube. 
If we treat a piece of dried horse dung and a piece of meat in the same way we shall in each case obtain ammonia gas.

We should expect to find that as plants require nitrogen they would absorb this gas from the air, as they do carbonic acid gas, through the leaves.

Careful experiments, however, have shown that they cannot do this, and have to obtain their nitrogen in other ways.

There is, however, one natural order of plants which can take up nitrogen from the air in a very curious way indeed. These plants belong to the order leguminosæ, and some of the commonest varieties of the order are vetches, peas, lupins, etc.

If we pull up one of these plants and examine the roots we shall find them covered with little lumps. On cutting through one of these lumps and examining it under a powerful microscope, we find it full of minute creatures, to which the name of bacteria have been given. These bacteria are able to absorb nitrogen gas, which surrounds the roots, and make it up into such compounds as the plant can absorb and use.

In this way the plant is fed by these bacteria from the free or uncombined nitrogen of the air.

No other common crop plants have, however, so convenient an arrangement, and, being unable to obtain nitrogen direct from the immense stock of free nitrogen in the air, they absorb the compounds of nitrogen which are formed (in part by the action 
of another set of organisms which carry on the process of nitrification), from the decay of vegetable stuff in the soil. By their means insoluble compounds of nitrogen are broken up and the nitrogen converted into nitrous and nitric acids which combine with lime and other bases in the soil.

If there is not sufficient store of decaying plants in the soil, the crops must be supplied with nitrogen by putting on the soil farmyard manure, which we have seen contains nitrogen, or any other vegetable or animal refuse.

Two compounds of nitrogen are now also very largely used for this purpose, and are prepared in enormous quantities for the farmer-sulphate of ammonia and nitrate of soda. Take a little dry sulphate of ammonia, mix with lime, and notice the smell of ammonia, showing that it contains nitrogen. In order to prove the presence of nitrogen in nitrate of soda we must treat it a little differently.

Dissolve a little sulphate of copper in water, and put in it a strip of zinc. It is at once coated with spongy copper.

Dissolve a little sodium nitrate in water, and put in some pieces of zinc covered with spongy copper, and warm gently for some time, then add some caustic soda and warm. The smell of ammonia will soon be quite distinct, showing that nitrate of soda also contains nitrogen.

Nitrate of soda and sulphate of ammonia are both very soluble in water (as we can easily see by 
dissolving a little of each in a little cold water), and are therefore very easily washed out of the soil.

For this reason they are often scattered over the soil after the wheat has begun to grow, so that they may be absorbed at once by the roots and not allowed to wash into the drains.

We can, however, enrich a soil with nitrogen suitable for plant food in another way.

We have learnt that leguminous plants can take up the nitrogen from the air.

If, then, we sow a crop of lupins, and after they have grown to maturity plough them in, we shall add to the store of nitrogen in the soil the decaying lupins yielding up to the next crop the nitrogen they obtained from the air. Or we may encourage the growth of clover by the application of lime or slag phosphate powder, and the root residue from the clover will enrich the soil for succeeding crops.

\section{Conclusion}

Let us now sum up what we know of the food of plants.

We have learnt of what substances a plant is composed.

We have found that it contains water, charcoal, nitrogen, and ash. 
The charcoal is obtained from the air by decomposing carbonic acid gas.

The water is obtained from the soil.

The nitrogen is obtained entirely from the soil, except in the case of leguminous plants, which can also obtain it from the air, which surrounds their roots in the soil.

The ash is obtained from the soil.

We have also learnt that the ash contains, among other substances, potash and phosphoric acid, and that these are apt to run short, as they exist in an available form in the soil in very small quantities.

We know that when a seed first begins to sprout it only requires to be supplied with water, as it contains food for the young plant in the form of oil, starch, and other substances. The young plant, however, develops in two directions - pushing a root into the earth, and stem and leaves into the air.

The root sucks up water from the soil, which, passing through the plant, evaporates from the leaves.

The water brings from the earth two kinds of food in solution: mineral food derived from the decayed rocks of which the soil is partly composed, and vegetable food, the most valuable ingredient of which is combined nitrogen in a soluble state, derived from the decay of plants in the soil, or from the organisms already described.

The leaves obtain food from the air in the form of carbonic acid gas, keeping the carbon or charcoal they require, and setting free oxygen again. 
We have also learnt that when we remove from the land the crops as fast as they grow up, we are taking away from the soil the store of mineral and vegetable food that the plant requires, and the soil becomes temporarily exhausted, and we have seen how this exhaustion of the soil can be remedied.

We have still much to learn about the nature of the soil and the changes which take place in the plants, for which purpose we must study very carefully the science of chemistry and then more advanced works on agricultural chemistry; for the present we must be content that we have gained some little insight into the way plants are fed. 



\section{APPENDICES}

I

\section{Notes on the Experiments}

BEFORE performing an experiment the student should write out carefully the question which he wishes to have answered by the experiment. While performing the experiment, he should note down what he does and what he observes, making a rough sketch of the apparatus used. When the experiment is completed, he should state his conclusion. These notes should then be carefully copied into another book, with a neat drawing of the apparatus. Several of the experiments in the text extend over hours, days, and weeks. Some can only be performed in spring or summer, and though many can be managed during the winter, it would be best to go through the book during spring and summer.

Experiment 5. A glass bottle with a wide tube, as shown in the drawing, would probably have to be specially made by a glass-blower. They can, however, be made very cheaply, and will, of course, be supplied in sets of apparatus. When such a bottle cannot be obtained, a fine glass tube could be introduced through the neck before the bees'-wax was poured in. This would do just as well. The water must be boiled to remove all dissolved air, and care taken that no air-bubbles are enclosed under the bees'-wax, as otherwise the water will not fall 
in the side tube, bubbles of gas collecting in the neck of the bottle instead. Any young healthy plant (flower or weed) will do for this experiment.

Experiment 6. The cork should be cut in half and fitted round the stem, so as not to injure the young bark.

Experiment 8. In some experiments where heating is necessary a spirit-lamp is described as being used, in others a Bunsen burner. If gas is available, a Bunsen burner, provided with a rose, will be found the most convenient. When gas cannot be obtained, a spirit-lamp will do instead for most of the experiments. When a high temperature is required, as in the burning to ash of the leaf, or the heating to redness of the soil, a spiritlamp will not do. Petroleum blowpipes can now be obtained which are perfectly suitable for this purpose, or a small charcoal fire will do as well.

Filter-paper is usually sold cut into circular disks. One of these should be folded in half, and then folded again into a quarter of the original size, then opened with the finger so as to form a little cone-shaped bag, and slipped into the glass funnel, and held there while it is moistened with a little water. It will then stay in position.

Experiment 12. The soil may take several hours to settle and leave the water clear, and is so finely divided that some of it will pass through the filter-paper if we try to filter it. This experiment therefore requires some patience.

Experiment 14. Condensers of various forms, and made of different materials, will do for this experiment. The one shown in the diagram is made of glass. A piece of stout block-tin tubing, surrounded by an outer tube of sheet-tin, does very well. The can described in Experiment 30 may be used to supply water to condense the steam, the tap being connected to $(a)$ by a piece of india-rubber tubing.

Another tin can, with a block-tin tube passing through a cork, can be used as a boiler. In fact, with the assist- 
ance of the village tinsmith, a very satisfactory still can be cheaply put together. Instead of a straight condenser, it is sometimes convenient to coil the tin tube into a spiral, and place it in a tub of water with the end of the tube coming through the side of the tub near the bottom.

Experiment 16. With a little practice a very complete separation of the sand and clay can be obtained by this means. The process is the same as that used in gold-washing, etc.

Experiment 17. The diagram in the text shows a very simple and cheap form of apparatus for drying substances at the temperature of boiling water.

The dry, clean, empty dish should first be weighed and the weight noted, then the soil introduced and the whole weighed again. The dish of soil after drying must be allowed to cool before being weighed again. It should be placed to cool in a desiccator or under a bell-jar (see Appendix II).

Fxperiment 19. A crucible made of platinum, while very suitable for this experiment, is somewhat expensive. A porcelain crucible, or platinum tray made by bending up the edges of a piece of platinum foil, will do very well. If a crucible is used, it should be left uncovered when over the flame and tilted a little on one side, so as to let the air freely circulate. Where gas is available it can be heated over a Bunsen burner. Where gas cannot be obtained, the petroleum blowpipe should be used. The pipeclay triangle is easily made. Three pieces of iron wire about 6 inches long and a clay tobacco pipe are required. Break off the stem of the pipe, three short pieces about 2 inches long, slip a picce of iron wire through each, and then twist together the ends of the iron wires, so as to make a triangular support for the crucible, with the twisted ends of the wires resting on the ring of the retort-stand. Such a stand will endure a high temperature for a long time, and will not injure the platinum, as a metal support would do. 
Experiment 21. The directions for drying, heating, and weighing already given apply to this experiment. The weight of ash obtained is, however, very small, and care must be taken to weigh very accurately. The ash should be kept, as it is required in Experiment 22.

Experiment 22. A very fine platinum wire should be used here. It should be heated in the flame for some time till it ceases to colour it, then moistened in a few drops of hydrochloric acid in a watch-glass, then dipped in the ash, and then placed in the flame again. It should be held in the outer part of the flame. A pale violet tint will be imparted to the flame, mixed with a yellow tint, due to the presence of soda. With a little practice, however, the potash violet flame will be easily recognised.

Experiment 23. About as much of the ash as would cover a sixpence will do for this experiment. It should bo emptied into a test-tube, about half an inch (measured on the side of the test-tube) of strong nitric acid added, and the test-tube warmed gently over the flame. Then add an inch of distilled water and filter into another test-tube. Add to 1 inch of the filtrate 1 inch of strong nitric acid, and 2 inches of molybdate of ammonia solution; shake up and warm gently, and allow it to stand for a few minutes. The yellow precipitate will be slowly formed.

Experiment 25. The end of the tube of the thistle funnel must of course dip below the water in the bottle so as to prevent the gas escaping up it. Fresh strong hydrochloric acid can be poured down the funnel from time to time to keep up the supply of gas. The marble should be broken up into pieces about the size of filberts. The gas set free is carbonic acid gas. It entirely prevents the charcoal from burning.

Experiment 28. This experiment and the two preceding it are due to Priestley, who first proved the exchange of carbon (charcoal) between the animal and 
vegetable kingdom. His experiments are published in his works, and are well worth reading.

Experiment 32. If an explosion is to be avoided great care must be taken to follow exactly the directions in the text. The beginner had better adopt the method described in the Note, but a teacher will find the experiment as described in the text very effective.

Chapter VII. Some valuable papers on the way in which nitrogen is supplied to plants will be found in the Journal of the Royal Agricultural Society, vol. ii. part iv. No. 8.

\section{II}

\section{On the Use of the Balance}

IN several of the experiments described in the text, accurate weighing is required in order to obtain a satisfactory result. In some cases the quantity to be weighed is very small, as for instance the ash left on burning leaves. It is indispensable, therefore, that an accurate balance and a good set of weights be obtained. It is almost impossible to weigh accurately unless the balance is enclosed in a glass case. The French weights (grammes) will be found the most convenient, as they are divided into tenths, and consequently can be easily added and subtracted.

Before trying any experiments in which weighing is required the student should practise weighing, so as to learn how to obtain an accurate result. On examining the balance he will notice a little brass stud in front. On turning this, the beam of the balance is raised off the brass pegs that support it, and is able to swing freely. 
Turn the brass stud slowly round, and bring the beam gently on to its supports again. It is now off the knife edges, and can no longer swing to and fro. It should always be in this position when not in use, and when anything is going to be placed on or removed from either pan.

Now open the glass front of the balance, dust the pans with a soft brush, and again turn the brass stud. The beam commences to swing to and fro, and the pointer to move backwards and forwards in front of the little ivory scale.

If the balance is equally weighted on both sides, the pointer will swing to about equal distances on both sides of the middle line of the scale. This can be accurately tested by noting the divisions on the scale. As the balance is slowly coming to rest, the pointer will swing a little less each time, and therefore in order to tell if the weights on each pan are exactly equal we should have to note down each swing and take the mean.

For most purposes it is sufficient to note that the pointer is very nearly equal in its swings on both sides of the dividing line. For instance, it may swing 4 on one side, 3 on the other side, 2 on the first side, and so on. Evidently the beam is equally balanced but slowly stopping.

If you wish to increase the swing of the beam gently fan the air with your hand near one of the pans. While noting the swings of the beam, close the glass front, otherwise currents of air entering the balance case will disturb the weighing.

As a rule, on trying the balance you will find the equilibrium imperfect. You will notice on the end of the beam a little nut running on a screw. By screwing this in or out the balance can be perfectly adjusted. Lower the beam, wind in or out as the case may be the little nut, raise the beam again, note the swings, and repeat until the balance is in equilibrium. You are now ready to weigh something. 
Take a piece of metal, say a lead bullet or a penny, see that it is clean and dry, and having lowered the beam, place it on one pan of the balance. Open the box of weights, and with the nippers provided for the purpose lift out the heaviest weight in the box and place it on the other pan. Now begin to raise the beam, turning the brass stud very gently, and noting the pointer. The pointer will probably move in one direction as the beam is being raised. We need not therefore raise the beam completely. Lower the beam, and if the weight is too heavy, remove it and place on the pan the next in order. If this is too light, add to it the next again. If too heavy with this addition, remove the last weight added and try the next. Do not try and guess at the weight of an object, but go systematically through the box. When you arrive at the tiny weights and are near to the true weight of the object, you will have to raise the beam completely and note the swings of the pointer. The glasis front should be closed during these final observations. Having got the balance exactly in equilibrium and lowered the beam, next look at the box of weights.

The brass weights beginning with 100 or 50 grammes go down to 1 gramme. The fractions of a gramme are of aluminium or platinum, and are tenths, hundredths, and thousandths of a gramme.

The tenths are marked $\cdot 5, \cdot 2, \cdot 1,1$. The hundredths are marked $\cdot 05, \cdot 02, \cdot 01, \cdot 01$; the thousandths or milligrammes are merely marked 5, 2, 2, 1, their size indicating their weight, or in some cases they are made of wire, which is bent to show the weight-thus, $\triangle \vee \vee-$; the number of bends indicating the number of milligrammes.

In the more expensive boxes each weight has its own little pigeon-hole. In cheaper boxes the fractions of a gramme are all mixed together. In the latter case it is as well before beginning a weighing to take a piece of 
paper and rule it into squares, marking each square as shown in the text, and placing the corresponding weight in it-

\begin{tabular}{|c|c|c|c|}
\hline 5 & $\cdot 2$ & $\cdot 1$ & $\cdot 1$ \\
\hline .05 & .02 & $\cdot 01$ & $\cdot 01$ \\
\hline .005 & .002 & .002 & $\cdot 001$ \\
\hline
\end{tabular}

Supposing our weights to have been so arranged and the weighing completed, before removing the weights from the balance pan examine the box and the diagram, and find the weight of the object by noting the weights missing. For instance, we notice that 30 grammes, 5 grammes, 2 grammes, $\cdot 5$ gramme, $\cdot 2$ gramme, $\cdot 1$ gramme, .05 gramme, 002 gramme are missing. Write these down in the following way and add:-

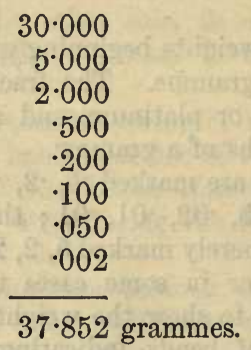

Next remove the weights from the pan, noting down the value of each as you return it to the box. On adding these up they should also come to $37 \cdot 852$ grammes. In this way a double check is obtained and mistakes in weighing are avoided. 
Every object must be clean, dry, and cool before weighing. On removing crucibles from heating over lamps, or objects from heating in a water-bath, they are best placed under a bell-jar on a glass plate, and a little dish of strong sulphuric acid should be placed under the bell-jar beside them, or they may be placed in an ordinary desiccator instead.

\section{NOTE}

For a class of twenty pupils, one balance and two drying ovens will be sufficient. Certain experiments, such as $13,18,20$, $25,30,31,32$, are best performed by the teacher before the class. The rest should be performed by the pupils themselves. In the list of apparatus those marked with a star should be provided for each pupil. One set of the other things will be sufficient. 


\section{LIST OF APPARATUS AND CHEMICALS REQUIRED}

\section{Apparatus}

Exper.

5. * Growing bottle 4 oz., with side tube to show level of water absorbed.

6. Chemical balance, 30 gramme load, in glass case, with set of weights from 30 grammes down to 1 milligramme.

"Set of 3 cork borers.

"* 3 blown glass bottles.

8. * 6 flat-bottomed flasks, $4 \mathrm{oz}$.

"* 6 glass funnels, $2 \frac{1}{2}$ in. diam.

"* 100 cut filter-papers, $4 \frac{3}{8}$ in. diam.

11. * 3 porcelain basins, 3 in. diam.

"* 4 in. square wire gauze for supporting basins, flasks, etc., on following retort stand.

"* 1 spirit-lamp and 1 pint methylated spirit, or Bunsen burner and 1 yard rubber tube where there is town gas, same value.

14. Tubulated retort, $16 \mathrm{oz}$.

Note.-One of each of the articles marked with an asterisk is sufficient for each student when several sets for students are being made up. 
Exper.

14. * Retort stand, with 2 rings and screws.

" Liebig's condenser, all glass.

\section{Condenser stand.}

" 2 yards india-rubber tube to supply condenser with water.

16. * Mortar and pestle, $4 \frac{1}{2}$ in. diam.

17. Tin drying chamber, double walls, for hot water, with tripod.

19. * Piece stout platinum foil, $4 \times 3$ in.

"* Pipeclay-covered triangle.

" Ignition burner for methylated spirit, latest design, for use in rural districts, or where there is town gas a foot blover and gas ignition burner will be supplied instead, same value.

22. * Fine platinum wire, 4 in.

* 2 watch-glasses.

23. * 12 test-tubes, $5 \times \frac{5}{8}$.

* Test-tube stand for six.

25. Gas generating bottle, 20 oz., fitted with rubber stopper, funnel tube and delivery tube.

26. Bell-jar with stopper at top, $8 \times 4$ in.

Ground glass plate, 6 in. square.

27. * Stoppered bottle with very wide mouth, $20 \mathrm{oz}$.

30. Aspirator fitted with brass tap.

" Rubber stopper for top of it.

" Rubber-jointed glass leading tubes.

" Extra rubber stopper for the bell-jar.

" Small beaker to hold lime water.

" Small tin candle-holder and candle.

" Charcoal chauffer on feet.

31. Deflagrating spoon and support.

32. 2 hard glass flasks for making oxygen, fitted with solid corks.

33. * Cylindrical jar on foot, $8 \times 2 \frac{3}{4}$ in. inside. 


\section{Chemicals}

In bottles.

$\frac{1}{4}$ oz. eosine red.

2 oz. bees'-wax.

4 oz. copper sulphate.

$6 \mathrm{oz}$. red lead.

2 oz. calcium sulphate.

$4 \mathrm{oz}$. hydrochloric acid, pure.

1 oz. ammonium molybdate.

$6 \mathrm{oz}$. nitric acid, pure.

1 oz. sodium phosphate.

1 oz. potassium carbonate.

4 oz. sulphuric acid, pure.

6 oz. sulphuric ether.

1 lb. hydrochloric acid, com.

1 oz. phosphorus.

1 oz. ammonium chloride.

4 oz. soda lime.

$1 \mathrm{oz}$. ammonium sulphate.

$1 \mathrm{oz}$ sodium nitrate.

$1 \mathrm{oz}$. granulated zinc.

6 oz. lime water.

4 lb. (parcel) charcoal.

1 oz. caustic soda.

Chemicals and bottles cost 118.

N.B. - If the case is sent by rail the chemicals in italics must be omitted, and an allowance of $4 \mathrm{~s}$. will be made for them.

\section{Specimens}

In 1 lb. stoppered specimen bottles.

Kainite.

Sulphate of potash.

Pearl ash. 
Bone meal.

Coprolites.

Apatite.

Phosphatic slag.

Soluble phosphate.

Guano.

Sulphate of ammonia.

Nitrate of soda.

Linseed.

Linseed oil.

Linseed cake.

The commercial names are used above.

Cost of specimens and bottles, 16 s.

\section{Total Cost}

\section{Apparatus}

Chemicals and bottles

Specimens and bottles

Packing cases, internal and external .

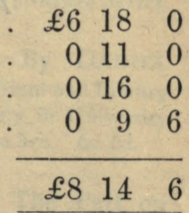

The above-mentioned Apparatus and Chemicals will be forwarded, carriage paid, to any station in the United Kingdom, when cash accompanies order, by

\section{Mr. WILLIAM HUME, \\ 1 LOTHIAN STREET, EDINBURGH;}

or

Messrs. J. J. GRIFFIN AND SONS,

22 Garrick Street, Covent Garden,

LONDON, W.C. 


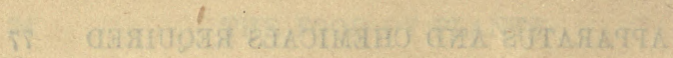

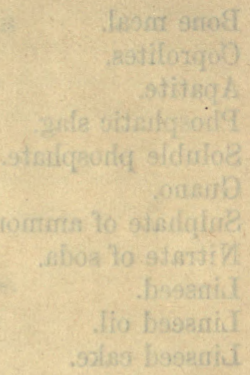

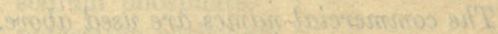

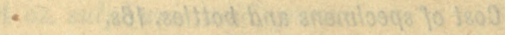

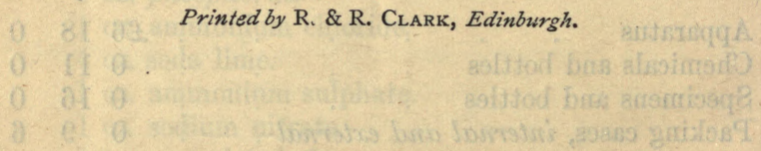

2. +1030,

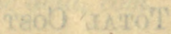

Printed by R. \& R. CLARK, Edinburgh. 


\section{BOTANICAL WORKS.}

THE STUDENT'S FLORA OF THE BRITISH ISLANDS.

By Sir J. D. Hooker, K.C.S.I., C.B., M.D., D.C.L. Oxon., LL.D. Cantab., F.R.S., F.L.S., F.G.S. Third Edition. Globe 8vo. ros. $6 \mathrm{~d}$.

FLOWERS, FRUITS, AND LEAVES. By Sir JoHN LubBоск, Bart., F.R.S., M.P., D.C.L., LL.D., Vice-Chairman of the London County Council, Principal of the London Working Men's College, and President of the London Chamber of Commerce. With numerous illustrations. Crown $8 v^{\circ}$. 4 s. $6 \mathrm{~d}$.

[Nature Series.

ON BRITISH WILD FLOWERS, considered in Relation to Insects. By the same Author. With numerous illustrations. Crown 8 vo. 4 s. 6 d.

[Nature Series.

THE COLOURS OF FLOWERS as illustrated in the British Flora. By Grant Allen. With illustrations. Crown 8vo. 3s. 6d.

[Nature Series.

FIRST BOOK OF INDIAN BOTANY. By DANIEL OLIVER, F.R.S., F.L.S., formerly Keeper of the Herbarium and Library of the Royal Gardens, Kew, and Professor of Botany in University College, London. With numerous illustrations. Globe 8vo. 6s. 6d.

LESSONS IN ELEMENTARY BOTANY. The Part on Systematic Botany based upon material left in manuscript by the late Professor HensLow. By the same Author. With numerous illustrations. Third Edition. Fcap. 8vo. 4s. 6d.

A COURSE OF PRACTICAL INSTRUCTION IN BOTANY. By F. O. Bower, D.Sc., F.L.S., Regius Professor of Botany in the University of Glasgow. Crown 8vo. ros. 6d.

[Abridged Edition, in the Press

FIRST LESSONS IN PRACTICAL BOTANY. By G. T. Bettany, M.A., B.Sc., F.L.S., late Lecturer on Botany in Guy's Hospital Medical School; formerly Examiner in Botany, Cambridge University Local Examinations. Pott 8vo. rs. 


\section{MESSRS. MACMILLAN AND CO.'S}

\section{BOOKS ON AGRICULTURE.}

ELEMENTARY LESSONS IN THE SCIENCE OF AGRICULTURAL PRACTICE. By Professor Henry TANner, M.R.A.C., F.C.S., Examiner in the Principles of Agriculture under the Government Department of Science. Fcap. 8vo. 3s. 6d.

FIRST PRINCIPLES OF AGRICULTURE. By the same Author. I8mo. Is.

THE PRINCIPLES OF AGRICULTURE. For Use in

Elementary Schools. By the same Author. Ex. fcap. 8vo.

THE ALPHABET OF THE PRINCIPLES OF AGRICULTURE. 6d.

FURTHER STEPS IN THE PRINCIPLES OF AGRICULTURE. Is.

ELEMENTARY SCHOOL READINGS ON THE PRINCIPLES OF AGRICULTURE FOR THE THIRD STAGE. Is.

THE ABBOT'S FARM ; or, Practice with Science. By the same Author. Crown 8vo. 3s. 6d.

DISEASES OF FIELD AND GARDEN CROPS, chiefly such as are caused by Fungi. By Worthington G. SMith, F.L.S. Fcap. 8vo. 4s. 6d.

THE SOIL IN RELATION TO HEALTH. By HENRY A. Miers, of the Natural History Department of the British Museum, and Roger Crosskey. Crown 8 vo.

[In the Press. TIMBER AND SOME OF ITS DISEASES. By H. MarShall WARD, F.R.S., Prof. of Botany, Royal Indian Engineering College, Cooper's Hill. Crown 8vo. 6s.

THE FOOD OF PLANTS. By A. P. LAURIE, M.A., Fellow of King's College, Cambridge, Adviser in Technical Education to the Bedfordshire County Council. Pott 8 vo. Is.

A PRIMER OF PRACTICAL HORTICULTURE. By J. Wright. Pott 8 vo. xs.

A MANUAL OF DAIRY WORK. By Professor JAMES MurR, of the Yorkshire College, Leeds. $18 \mathrm{mo}$. xs.

A TEXT-BOOK OF TROPICAL AGRICULTURE. By H. A. Alford NicholLS, M.D., F.L.S. With illustrations. Crown 8 vo. Cloth. 6s.

ACADEMY - "The qualifications of Dr. Nicholls to write a book on the subject are almost unique. He directs with success a varied plantation in Dominica. ... He is well known as a good naturalist, and has now proved that he is also a lucid writer. He has carried all these qualities into the production of a text-book which is the model of a technical manual. It is full of personal observation and first-hand knowledge, set forth with simplicity and modesty."

SCOTSMAN-" An admirable, practical, and well-informed text-book, not compiled from books, but written at first hand from the experiences of many years. The popularity which the work has gained in the West Indies will be extended wherever it is known, and students of agriculture, as well as small cultivators who intend settling in tropical countries, will find it abundantly useful." 


\section{MESSRS. MACMILLAN AND CO.'S}

\section{DOMESTIC ECONOMY CLASS BOOKS.}

HOUSEHOLD MANAGEMENT AND COOKERY. Compiled for the London School Board. By W. B. TEGETMEIER. 18mo. Is.

A PRIMER OF DOMESTIC ECONOMY. By Edith A. BARNETT and H. C. O'NEILL. 18mo. Is.

SCOTSMAN-" It is in its way unique among school books, touching the fringe of a great variety of subjects-hygiene, economics, physiology, cooking, medicine, and the sciences dealing with money. Of these it says a little that every housekeeper ought to know, and opens the way for more. It is an admirable school book."

SATURDAY REVIEW-"A capital little book for the young householder."

THE SCHOOL COOKERY-BOOK. Compiled and Edited by C. E. Guthrie Wright, Hon. Sec. to the Edinburgh School of Cookery. 18mo. Is.

THE MIDDLE CLASS COOKERY-BOOK. Edited by the Manchester School of Domestic Cookery. Fcap. 8vo. is. 6d.

FIRST LESSONS IN THE PRINCIPLES OF COOKING. BY Lady BARKER. I8mo. Is.

HINTS TO HOUSEWIVES on several points, particularly on the preparation of economical and tasteful dishes. BY Mrs. FrEDERICK. Crown 8vo. Is.

FIRST LESSONS ON HEALTH. By J. BERNERs.
I8mo.

THE CARE OF INFANTS. A Manual for Mothers and Nurses. By Sophia Jex-Blake, M.D. I8mo. is.

a GUide to District NURSES. By Mrs. Craven. Crown 8 vo. 2 s. 6 d.

CUTTING-OUT AND DRESSMAKING. From the French of Mdlle. E. Grand'homme. With Diagrams. I8mo. Is.

DRESSMAKING. A Technical Manual for Teachers. By Mrs. Henry Grenfell. With Preface by Miss F. L. Calder. Pott 8vo. is.

MANUAL OF NEEDLEWORK. By. Miss ElizabeTH ROSEveAr, Lecturer on Needlework, Training College, Stockwell College. With Diagrams. Crown 8 vo.
[In the Press. 


\section{MACMILLAN'S SCIENCE PRIMERS.}

Under the joint editorship of Prof. HuXLEY, Sir H. E. Roscoe, and Prof. Balfour Stewart.

Pott 8vo. Is. each.

INTRODUCTORY. By Professor Huxley.

CHEmistry. By Sir Henry Roscoe, F.R.S. With Illustrations and Questions.

PHYSICS. By BALFOUR STEWART, F.R.S. With Illustrations and Questions.

PHYSICAL GEOGRAPHY. By Sir A.

GEIKIE, F.R.S. With Illustrations and Questions.

GEOlOGY. By Sir Archibald Geikie, F.R.S.

PHYSiOlOGY. By Michael Foster, F.R.S. ASTRONOMY. By J. N. LOCKYER, F.R.S. BOTANY. By Sir J. D. HoOker, C.B. LOGIC. By W. Stanley Jevons, F.R.S. POLITICAL ECONOMY. By W. Stanley JEVons, LL.D., M.A., F.R.S. 


\section{UNIVERSTTY OF TORONTO LIBRARY}

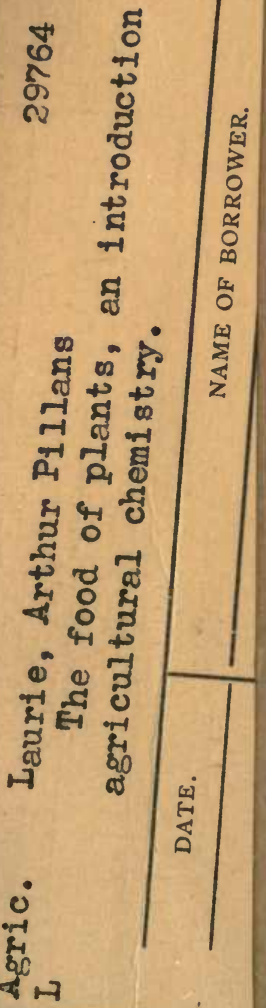

remove.

the card

from this

Pocket.

Acme Library Card Pocket

Under Pat. "Ref. Index File."

Mado by LIBRARY BUREAU 


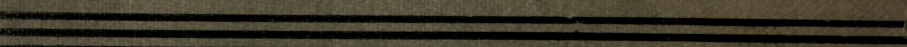

